\title{
Late Gestation Alterations in Fetal Pulmonary Lactate Metabolism in Vivo
}

\author{
REBECCA A. SIMMONS AND VALERIE E. CHARLTON \\ Division of Neonatology, Department of Pediatrics and Cardiovascular Research Institute, University of \\ California, San Francisco, California 94143
}

\begin{abstract}
We have previously shown that lactate is produced by the ovine fetal lung. Inasmuch as factors that might affect lactate production, such as pulmonary glucose and oxygen uptake, change late in gestation we investigated whether pulmonary lactate metabolism also changes. Eleven chronically catheterized fetal lambs were studied over 119-141 d gestation. Lactate, glucose, and oxygen concentrations were measured in the pulmonary artery (PA) and vein while lung blood flow was determined using labeled microspheres. Between early studies ( $\leq 127 \mathrm{~d})$ and studies near term ( $\geq 134$ d) PA lactate levels did not change, but due to increasing pulmonary blood flow, lung lactate delivery rose $51 \%(p<0.05)$. Because of a decline in PA glucose, lactate also made up a larger fraction of the major nonnitrogenous substrate in PA blood near term ( $p$ $<0.001$ ). Despite this, no net pulmonary uptake of lactate occurred. Lactate production continued, but decreased by $80 \%$ between early and late studies $(p<0.05)$ and the maximum fraction of glucose uptake that could be accounted for by lactate production dropped from 0.78 to $0.20(p<0.025)$. Correlations were found between lung lactate production and both glucose delivery $(p<0.005)$ and PA glucose concentration $(p<0.05)$. The ratio between lactate production and glucose uptake also correlated with PA glucose $(p<0.05)$. No relationships were observed between lactate production and PA oxygen content, oxygen delivery, lactate concentration, or lactate delivery. The decreasing fraction of glucose uptake explained by lactate production suggests that metabolism of pulmonary glucose is altered near term. The correlation between decreasing glucose delivery and declining lactate production also suggests that glucose itself influences this change. (Pediatr Res 27: 274-277, 1990)
\end{abstract}

\section{Abbreviations}

PA, pulmonary artery

$P V$, pulmonary vein

In previous studies in chronically catheterized fetal sheep, we found that glucose is taken up by the fetal lung and lactate is produced (1). During late gestation, the average quantity of lactate produced is equivalent to about $50 \%$ of pulmonary glucose uptake. However, metabolic factors that may influence lung lactate metabolism are not static during gestation. Near term,

Received March 20, 1989; accepted October 19, 1989.

Correspondence and reprint requests Dr. Valerie E. Charlton, University of California Department of Pediatrics and CVRI Box 0748, San Francisco, CA 94143.

Supported by an American Lung Association of California Fellowship (R.A.S.) NIH Research Career Development Award HD00542 (V.E.C.), and NIH SCOR Award HL27356 (V.E.C.). pulmonary arterial glucose concentration and pulmonary glucose uptake decline, whereas pulmonary delivery of oxygen increases (1). We, therefore, investigated whether lactate metabolism in the fetal lung changes with gestation or with either pulmonary delivery of glucose or oxygen. Further, because lactate levels themselves might affect lung metabolism, we investigated the relationship between pulmonary lactate concentration and both lung lactate production and glucose use.

\section{MATERIALS AND METHODS}

Surgical preparation and recovery. Eleven mixed Western, breed-dated, pregnant sheep of 115 to $125 \mathrm{~d}$ gestation were surgically prepared by methods described previously $(1-3)$. With the ewe under spinal anesthesia (induced by $1 \%$ tetracaine) and pentobarbital analgesia, catheters were inserted into a maternal hindlimb artery and vein. The maternal abdomen and uterus were then opened.

Eleven fetal lambs were catheterized: 10 singletons and one of a set of twins. Fetal anesthesia was accomplished with locally injected $1 \%$ xylocaine and i.v. pentobarbital. Fetal catheters (0.030 inch inner diameter) were inserted into either a femoral artery and vein (eight animals) or into a carotid artery and jugular vein (three animals). In each fetus the thorax was opened and a 20-gauge Teflon catheter, fitted on a piece of polyvinyl tubing, was inserted into the main pulmonary artery (3). A catheter $(0.011$ inch inner diameter) was also inserted into a distal pulmonary vein and threaded up into a major vein draining the left upper lobe of the lung. After closure of the fetal incision, a multipore amniotic fluid catheter was anchored in the uterus and all catheters were exteriorized to the maternal flank.

Antibiotics ( 1 million $U$ of penicillin and $250 \mathrm{mg}$ of gentamicin) were administered to the mother and into the amniotic cavity at the time of surgery. During postoperative recovery, antibiotics were given for $5 \mathrm{~d}$, as above, and the mother was fed ad libitum.

Study protocol. After recovery, pulmonary delivery and uptake of lactate, glucose, and oxygen were measured in each fetus. At study, fetal blood samples were drawn simultaneously from the fetal PA and PV while pulmonary blood flow was measured using a radiolabeled microsphere technique (2). Whole blood samples were analyzed for concentrations of lactate, glucose, $\mathrm{Hb}$, oxygen saturation, $\mathrm{pH}$, and $\mathrm{PaO}_{2}$. Two sets of blood samples and two measurements of blood flow were obtained at each study and averaged to determine a study value. A blood sample was also drawn from the maternal artery during each study. This was used to measure maternal metabolite levels and blood gases.

Studies were repeated one to two times weekly. The 44 studies reported here were performed between 119 and $141 \mathrm{~d}$ gestation in healthy animals at least $4 \mathrm{~d}$ postsurgery and 2 or more $\mathrm{d}$ before spontaneous delivery or fetal death. Arterial blood gases were normal in all ewes and fetuses, with fetal femoral or carotid arterial $\mathrm{pH}>7.30$. Because of occasional difficulties with catheter 
sampling, samples were not always available from each vessel or for every metabolite.

Analytical methods. Whole blood samples for lactate and glucose were analyzed in duplicate. The samples were deproteinized immediately with iced reagents, and frozen at $-80^{\circ} \mathrm{C}$ until assayed. Arterial and venous samples from each animal were analyzed in the same assay run. Lactate concentration was determined using a lactate dehydrogenase assay and glucose by an enzymatic, colorimetric glucose oxidase method (both assays from Sigma Chemical Co., St. Louis, MO). The mean percentage error between duplicate samples was $1.5 \%$ for lactate and $1.9 \%$ for glucose.

Blood gases were measured immediately after blood drawing, on a Corning $158 \mathrm{pH} /$ blood gas analyzer (Corning Medical, Medford, MA). Hb concentration and oxygen saturation were measured, in duplicate, on a Radiometer-Copenhagen OSM 2 hemoximeter (The London Co., Westlake, $\mathrm{OH}$ ). Our mean percentage error between duplicate measurements of $\mathrm{Hb}$ was $1.0 \%$ and for oxygen saturation it was $0.8 \%$. Using these measurements oxygen content was calculated from the formula (4): $\mathrm{O}_{2}$ content $(\mathrm{mL} / \mathrm{dL})=$

\section{$\left[1.34 \times \mathrm{Hb} \times \mathrm{O}_{2}\right.$ saturation $\left.(\%)\right]+\left[0.003 \times \mathrm{PaO}_{2}(\mathrm{~mm} \mathrm{Hg})\right]$}

Calculations. Delivery of metabolites and oxygen to the lung was calculated as the PA concentration times pulmonary blood flow. Substrate uptake or production was calculated by multiplying the PA-PV difference times pulmonary blood flow. For purposes of calculating substrate uptake, blood draining the left upper pulmonary lobe was assumed to be representative of blood draining the lung as a whole. Similarly, pulmonary blood flow was taken as representing total lung flow, because we have previously determined that correction of blood flow for substrate delivery and uptake via the bronchial circulation makes a negligible difference in these calculations (1).

The maximum fraction of pulmonary glucose uptake that could be accounted for by pulmonary lactate production was calculated as lactate production $(\mu \mathrm{g} / \mathrm{min}) /$ glucose uptake $(\mu \mathrm{g} /$ $\min$ ), because if all the lactate produced was derived from glucose, $1 \mu \mathrm{g}$ of glucose would be consumed for each $\mu \mathrm{g}$ of lactate made.

Average birth wt of the fetuses studied was $3678 \mathrm{~g}$, at a mean gestation of $138 \pm 2 \mathrm{~d}$. The average length of study in individual animals was $12 \pm 1.5 \mathrm{~d}$. Total lung wet wt averaged $85 \pm 8 \mathrm{~g}$, and the mean lung/body wt ratio was $2.1 \pm 0.3 \%$; all these values were within the normal range (5-7). The wet wt of the instrumented left upper lobes of the lung in study animals were $11 \pm$ $1 \mathrm{~g}$, similar to the $13 \pm 2 \mathrm{~g}$ wt of left upper lobes in animals in our lab without pulmonary catheters (Simmons RA, Charlton VE, personal observation).

Statistical analysis. All data are expressed as the mean \pm SEM. An analysis of variance followed by the Fisher's protected least significant difference was used to compare measurements of PA substrate levels, substrate delivery, PA-PV substrate differences, and pulmonary substrate production or uptake obtained during early, mid-, and near term studies $(\leq 127 \mathrm{~d},>127$ and $<134 \mathrm{~d}$, and $\geq 134 \mathrm{~d}$ gestation, respectively) (8). Comparisons between first and last studies within the same animals were made using the paired $t$ test (8). Relationships between either the rate of lactate production or the lactate production/glucose uptake ratio versus pulmonary arterial concentration or delivery of substrate were defined by first establishing indicator variables for each fetus, that linked them to their data points, and then performing multiple regression analysis (9). A $p$ value of 0.05 was taken to imply a significant difference or correlation, whereas $p<0.1$ was noted as suggesting a trend.

\section{RESULTS}

Over the period of gestation studied $(119-141 \mathrm{~d}$, term $=145$ d), pulmonary blood flow increased by $65 \pm 28 \%$. This increase was similar to our previous findings (1) and was consistent with prior measurements made in groups of younger and older animals $(10,11)$.

The average concentration of lactate in the PA was $15.17 \pm$ $0.38 \mathrm{mg} / \mathrm{dL}(1.69 \pm 0.04 \mathrm{mM})(n=44)$ and did not change significantly as gestation advanced. However, lactate delivery, which averaged $12.49 \pm 0.91 \mathrm{mg} / \mathrm{min}(139 \pm 10 \mu \mathrm{mol} / \mathrm{min})(n$ $=30$ ), increased as the fetus matured due to the increase in pulmonary blood flow. Serial values for lactate delivery obtained during the early ( $\leq 127$ d gestation), mid-, and near term ( $\geq 134$ d) studies are given in Table 1 .

Inasmuch as PA glucose levels fell from $23.35 \pm 1.30 \mathrm{mg} / \mathrm{dL}$ $(1.30 \pm 0.07 \mathrm{mM})(n=18)$ to $16.21 \pm 1.17 \mathrm{mg} / \mathrm{dL}(0.90 \pm 0.06$ $\mathrm{mM})(n=15)(p<0.025)$ between the early and late studies, lactate accounted for a progressively larger fraction of the major nonnitrogeneous fetal fuels (i.e. lactate and glucose) in PA blood as gestation advanced. In measurements made at $\leq 127 \mathrm{~d}$, the ratio between PA lactate, $\mathrm{mg} / \mathrm{dL} /(\mathrm{PA}$ lactate \pm PA glucose, $\mathrm{mg} /$ $\mathrm{dL})$ was $0.40 \pm 0.01(n=18)$ compared to $0.50 \pm 0.02(n=15)$ for measurements made at $\geq 134 \mathrm{~d}(p<0.001)$. When calculated in molar units, $\mathrm{PA}$ lactate, $\mathrm{mM} /(\mathrm{PA}$ lactate, $\mathrm{mM} \pm \mathrm{PA}$ glucose, $\mathrm{mM})$, the respective values were $0.57 \pm 0.01$ and $0.67 \pm 0.02(p$ $<0.001$ ). Furthermore, where flow measurements were available, the quantity of lactate delivered to the lung at $\geq 134 \mathrm{~d}$ equaled or exceeded glucose delivery, $14.60 \pm 1.55 \mathrm{mg} / \mathrm{min}(162 \pm 17$ $\mu \mathrm{mol} / \mathrm{min})$ for lactate versus $13.62 \pm 1.55 \mathrm{mg} / \mathrm{min}(76 \pm 8$ $\mu \mathrm{mol} / \mathrm{min})$ for glucose $(n=10)$.

Throughout the period of study, there was a positive PV-PA difference for lactate across the lung, indicating net lactate production. The average PV-PA difference in lactate was $727 \pm 135$ $\mu \mathrm{g} / \mathrm{dL}(81 \pm 15 \mu \mathrm{M})(n=33)$. As can be seen in Table 1 , this difference tended to decrease as the fetus matured, with the average PV-PA difference for lactate falling $55 \%$ from the first to last wk of the study period. Within individual lambs, in whom first and last studies were separated by a mean of $14 \pm 2 \mathrm{~d}$, the PV-PA difference for lactate fell by $477 \pm 310 \mu \mathrm{g} / \mathrm{dL}(53 \pm 34$ $\mu \mathrm{M})(n=6),(p<0.05)$.

Values for lactate production by the lung are given in Table 1. Overall production averaged $421 \pm 101 \mu \mathrm{g} / \mathrm{min}(4.68 \pm 1.12$ $\mu \mathrm{mol} / \mathrm{min})(n=20)$ but as can be seen in Table 1 , lactate production fell $80 \%$ as gestation progressed.

We have previously noted that pulmonary uptake of glucose decreases in late gestation, as pulmonary arterial glucose levels fall (1). However, the decrease in lactate production reported here was much greater than the change in pulmonary glucose use. Assuming that all the lactate was derived from glucose, the fraction of glucose uptake that could be accounted for by lactate production, i.e. lactate production $(\mu \mathrm{g} / \mathrm{min}) /$ glucose uptake $(\mu \mathrm{g} /$ min), decreased from $0.78 \pm 0.18(n=8)$ at $\leq 127 \mathrm{~d}$ to $0.20 \pm$ $0.10(n=7)$ at $\geq 134 \mathrm{~d}(p<0.025)$.

Both lactate production and the ratio between lactate produc-

Table 1. Lactate metabolism of ovine fetal lung during the 3rd trimester (mean \pm SEM)

\begin{tabular}{|c|c|c|c|}
\hline $\begin{array}{c}\text { Gestational } \\
\text { age } \\
\text { (d) }\end{array}$ & $\begin{array}{c}\text { Lactate delivery } \\
\mathrm{mg} / \mathrm{min} \\
(\mu \mathrm{mol} / \mathrm{min})\end{array}$ & $\begin{array}{c}\text { PV-PA lactate } \\
\mu \mathrm{g} / \mathrm{dL} \\
(\mu \mathrm{M})\end{array}$ & $\begin{array}{l}\text { Lactate production } \\
\qquad \mu \mathrm{g} / \mathrm{min} \\
(\mu \mathrm{mol} / \mathrm{min})\end{array}$ \\
\hline$\leq 127$ & $\begin{array}{c}9.65 \pm 1.45 \\
(107 \pm 16) \\
(n=10)\end{array}$ & $\begin{array}{c}1014 \pm 219 \\
(113 \pm 24) \\
(n=16)\end{array}$ & $\begin{array}{c}660 \pm 143 \\
(7.33 \pm 1.59) \\
(n=9)\end{array}$ \\
\hline$>127$ and $<134$ & $\begin{array}{c}13.21 \pm 1.42 \\
(147 \pm 16) \\
(n=10)\end{array}$ & $\begin{array}{c}470 \pm 210 \\
(52 \pm 23) \\
(n=5)\end{array}$ & $\begin{array}{c}390 \pm 250 \\
(4.33 \pm 2.78) \\
(n=4)\end{array}$ \\
\hline$\geq 134$ & $\begin{aligned} & 14.60 \pm 1.55 \\
&(162 \pm 17) \\
&(n=10)^{*}\end{aligned}$ & $\begin{array}{l}455 \pm 144 \\
(51 \pm 16) \\
(n=12) \dagger\end{array}$ & $\begin{array}{c}133 \pm 115 \\
(1.48 \pm 1.28) \\
(n=7)^{*}\end{array}$ \\
\hline
\end{tabular}

$* p<0.05, \dagger p<0.06$ for $\leq 127 \mathrm{~d}$ versus $\geq 134 \mathrm{~d}$. 
tion and glucose use were found to be related to the amount of glucose available to the lung. As pulmonary glucose delivery or glucose concentrations fell, lactate production, PV-PA differences of lactate, and the fraction of glucose uptake that could be accounted for by lactate production all decreased. The correlation between lactate production and glucose delivery to the lung is shown in Figure 1. (Even if the one study with very high glucose delivery is removed, this correlation remains significant.) Correlations were also found between lactate production and the PA glucose concentration ( $r=0.42, n=20, p=0.06)$ and between the PV-PA difference for lactate and PA glucose concentration $(r=0.38, n=33, p<0.05)$. The relationship between the lactate production/glucose uptake ratio and PA glucose is presented in Figure 2.

Contrary to our expectations, the quantity of lactate produced was not related to either PA oxygen content or pulmonary oxygen delivery. Similarly the PV-PA difference of lactate did not correlate with either PA oxygen content or oxygen delivery.

Interestingly, when the effects of lactate itself were analyzed, no direct relationship was found between lactate delivery to the lung and lactate production, or between PA lactate concentration and lactate production. High pulmonary arterial lactate concentrations did not result in a net pulmonary uptake of lactate.

In contrast, lactate concentration appeared related to pulmonary glucose uptake. When PA lactate was above the midrange of our concentrations, i.e. more than $15 \mathrm{mg} / \mathrm{dL}(1.67 \mathrm{mM})$, glucose uptake averaged $338 \pm 273 \mu / \mathrm{min}(1.88 \pm 1.51 \mu \mathrm{mol} /$ $\min )(n=8)$. Whereas at lactate concentrations less than $15 \mathrm{mg} /$ $\mathrm{dL}$, average glucose uptake was 3-fold more at $1198 \pm 204 \mu \mathrm{g} /$ $\min (6.66 \pm 1.13 \mu \mathrm{mol} / \mathrm{min})(n=13),(p<0.05)$.

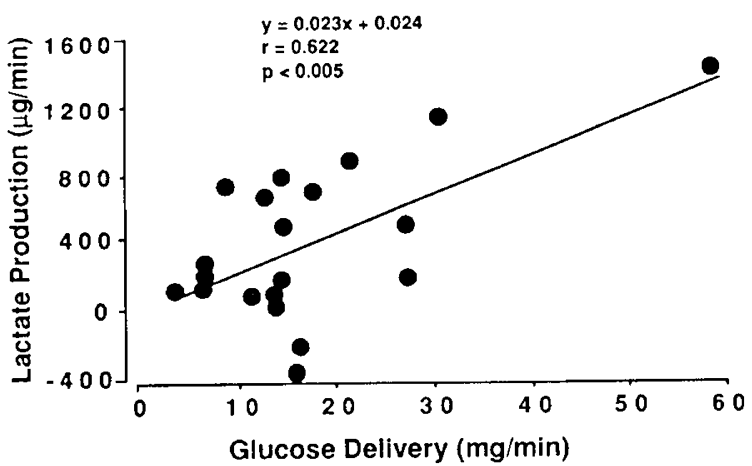

Fig. 1. The relationship between glucose delivery to the lung and lactate production by the lung. Since lactate has half the molecular wt of glucose, expression of this relationship in molar units would double the slope of the regression equation.

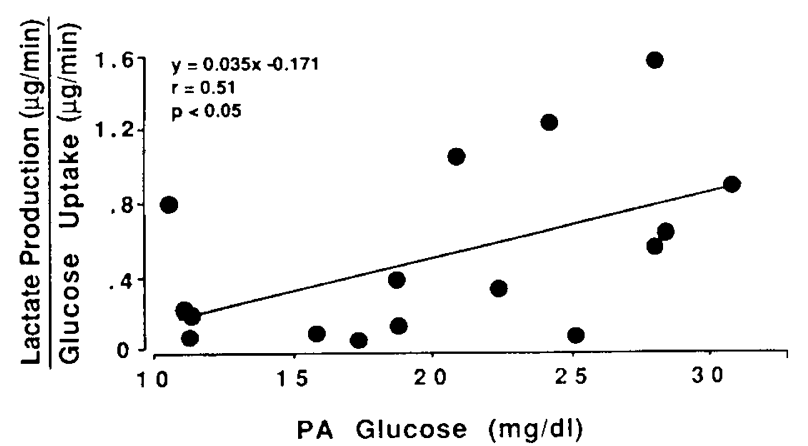

Fig. 2. The relationship between pulmonary arterial glucose concentration and the maximum fraction of glucose uptake across the lung that could be accounted for by lactate production (lactate production/glucose uptake). Taking into account that $2 \mathrm{~mol}$ of lactate are produced from each mole of glucose, expression of the latter ratio in molar units [as (lactate $\mu \mathrm{M} / \mathrm{min} \div 2) /($ glucose $\mu \mathrm{M} / \mathrm{min})]$ would not change the calculated values nor the relative slope of the regression.
Maternal levels of glucose, lactate, and oxygen were stable throughout this period of gestation and did not appear to influence the changes noted in fetal values.

\section{DISCUSSION}

The aim of this study was to investigate whether pulmonary lactate metabolism in vivo changes with gestation or with alterations in either pulmonary arterial concentration or pulmonary delivery of glucose and oxygen. In addition we sought to identify any relationship between pulmonary lactate levels and lactate production or glucose use.

Our results indicate that the relative and absolute amounts of lactate reaching the lung change as the fetus matures. The quantity of lactate delivered to the lung increases $51 \%$ from the first to the last wk of the gestation period studied and the proportion of major nonnitrogenous fetal substrate (i.e. lactate and glucose) in PA blood that is lactate also increases. By the end of gestation, half of this substrate reaching the lung is lactate. Inasmuch as lung size is increasing by approximately $24 \%$ over this time period $(7,12)$ (Simmons RA, Charlton VE, personal observation) lactate delivery per $U$ wt of lung is increasing nearly twice as fast.

However, despite the increasing delivery of lactate to the lung, lactate production was found to continue and there was no evidence of pulmonary lactate uptake. Further, we did not find that the rate of lactate production was influenced by either lactate concentration or pulmonary lactate delivery. These in vivo findings are in agreement with some prior in vitro studies and in conflict with other in vitro results.

Near term, fetal rat, type II pneumocytes in short-term culture and perfused lungs from adult rats have been shown to produce lactate from glucose $(13,15)$. Experiments in fresh isolated perfused adult rat lungs have demonstrated no effect of added lactate on the rate of lung lactate production, over perfusate lactate concentrations of $0-45 \mathrm{mg} / \mathrm{dL}(0-5 \mathrm{mM})(14,15)$. However, other studies done on isolated perfused adult rat lungs, have reported that lactate in perfusate concentrations of $18 \mathrm{mg} / \mathrm{dL}(2$ $\mathrm{mM}$ ) decreases lactate production by $95 \%$ (16). Isolated, near term, fetal rat type II pneumocytes have also been found to decrease their rate of lactate production when lactate is added to the culture media, and at extracellular lactate levels of $45 \mathrm{mg} /$ $\mathrm{dL}(5 \mathrm{mM})$ they show net lactate utilization (13).

The difference in results between these latter in vitro experiments and our findings might be due to species differences, differences in developmental state of the in vitro tissues, or to the high concentration of lactate used in the culture media compared to ovine in vivo levels. However, we speculate that ambient glucose levels are, in large part, affecting the rate of lactate production and the response of lung tissue to varied lactate concentrations. In vivo, glucose levels correlate directly with lung lactate production. Inasmuch as glucose levels are normally low in the ovine fetus, it is interesting to note that the in vitro studies in agreement with our findings $(14,15)$ were carried out at relatively lower glucose concentrations [101-108 $\mathrm{mg} / \mathrm{dL}(5.6-6.0 \mathrm{mM})]$ compared to glucose levels in the discordant studies [126-180 mg/dL (7-10 mM)] $(13,16)$. Furthermore, the isolated lungs perfused with $180 \mathrm{mg} / \mathrm{dL}(10 \mathrm{mM})$ glucose had higher baseline rates of lactate production $[630 \mu \mathrm{g} / \mathrm{h} / \mathrm{g}(7.0$ $\mu \mathrm{mol} / \mathrm{h} / \mathrm{g})](16)$ than did lungs perfused with $101-108 \mathrm{mg} / \mathrm{dL}$ glucose $[441-468 \mu \mathrm{g}$ of lactate $/ \mathrm{h} / \mathrm{g}(4.9-5.2 \mu \mathrm{mol} / \mathrm{h} / \mathrm{g})](14,15)$. At lower glucose levels, lactate production may already be decreased and unresponsive to further modulation by lactate.

In fact, the effect of lactate concentration on lung lactate metabolism noted in some in vitro studies appear to be related to changes in lung glucose use. In vivo we found that higher pulmonary lactate levels are associated with decreased glucose use. In one of the perfused rat lung studies mentioned above, lung glucose use was also measured and the addition of lactate 
to the perfusate was found to decrease glucose use by $63 \%$, concurrent with the decrease in lactate production (16). The mechanism for the effect of lactate on glucose is unclear. It may be possible that lactate directly or indirectly inhibits glycolysis $(16,17)$.

Although we found no pulmonary utilization of lactate as gestation advanced, we did find a steep decline in lung lactate production and a decrease in the fraction of lung glucose uptake that could be accounted for by lactate production. Both correlated with the late gestation drop in pulmonary arterial glucose concentration, which we have previously described (1). These associations suggest that glucose is influencing maturation of the fetal lung and the change in metabolic fate of glucose from lactate production to other metabolic pathways. We speculate that the reduction in lung lactate output noted may reflect the diversion of the end products of glycolysis into surfactant lipid production. Rapid incorporation of labeled lactate into lung phospholipids has been found in isolated adult rat lungs (15). Alternative routes for glucose metabolism, which may also become more active, include the citric acid cycle and the pentosephosphate shunt pathway (18). Increased citric acid cycle activity has been found in fetal rat lung slices taken from animals near term (18). This activity would logically increase in vivo near term, coincident with the increase in pulmonary oxygen delivery and use that we have described (1). In studies performed on isolated near-term fetal rat type II pneumocytes, the pentose shunt pathway has been found to be a preferred pathway for glucose metabolism (19). This latter pathway is an important source of NADPH for fatty acid synthesis (20) and would also logically become active in vivo at the end of gestation, when surfactant synthesis is increasing.

Finally, hypoxia has been shown to increase pulmonary lactate production in vitro. Studies using isolated perfused adult rat lungs as well as fetal rat type II pneumocytes have demonstrated an elevated rate of lactate production under conditions of significantly reduced oxygen availability $(13,14,16,19)$. However, our results show that the usual changes in pulmonary oxygenation found during normal gestation do not influence lung lactate production. Although oxygen delivery to the lung increases with gestation as mentioned (1), and pulmonary lactate production declines, no correlation between the two was observed. Our results suggest that the high rate of lactate production in the younger fetal lung represents an earlier metabolic developmental stage and not pulmonary hypoxia.

In summary, lactate metabolism changes as the fetal lung matures. Lactate production and the fraction of glucose uptake that can be accounted for by lactate production fall. Both changes correlate with the decrease in glucose found over this period, suggesting that glucose levels are affecting metabolic maturation. The change in lactate production relative to glucose uptake also indicates that the metabolic fate of pulmonary glucose is altered. The late gestational increase in lung lactate delivery noted may also secondarily influence metabolic maturation of the lung by decreasing the rate of glucose use.

\section{REFERENCES}

1. Simmons RA, Charlton VE 1988 Substrate utilization by the fetal sheep lung during the last trimester. Pediatr Res 23:606-611

2. Rudolph AM, Heymann MA 1980 Methods for studying the circulation in utero. In: Nathanielsz PW (ed) Animal Models in Fetal Medicine I. Elsevier/ North, Holland, pp 1-57

3. Iwamoto H, Rudolph AM, Bristow J 1984 Fetal organ metabolism-techniques for catheterization of renal, pulmonary and hepatic veins in sheep. In Nathanielsz P (ed) Monographs in Fetal Physiology 5: Animal Models in Fetal Medicine IV. Perinatology Press, Ithaca, NY, pp 1-18

4. Comroe J 1975 The transport of oxygen by blood. In: The Physiology of Respiration. Yearbook Medical, Chicago, pp 183-196

5. Charlton V, Johengen M 1985 Effects of intrauterine nutritional supplementation on fetal growth retardation. Biol Neonate 48:125-142

6. Charlton V, Johengen M 1987 Fetal intravenous nutritional supplementation ameliorates the development of embolization-induced growth retardation in sheep. Pediatr Res 22:55-61

7. Barcroft J 1946 Growth of the body and its constituent parts. In: Researches on Prenatal Life. Blackwell Scientific, Oxford, pp 29-41

8. Feldman D, Gagnon J, Hoffman R, Simpson J 1988 Statview, version 1.02. Abacus Concepts Inc, Berkeley, CA

9. Kleinbaum DG, Kupper LL 1978 Applied Regression Analysis and Other Multivariable Methods. Duxbury Press, North Scituate, MA

10. Rudolph A, Heymann M 1970 Circulatory changes during growth in the fetal lamb. Circ Res 26:289-299

11. Creasy R, De Swiet M, Kahanpaa K, Young W, Rudolph A 1973 Pathophysiologic changes in the foetal lamb with growth retardation. In: Cross $\mathrm{K}$ (ed) Foetal and Neonatal Physiology, Proceedings of the Sir Joseph Barcroft Centenary. Cambridge University Press, Cambridge, pp 398-402

12. Schellenberg JC, Liggins GC 1987 Elastin and collagen in the fetal sheep lung I. Ontogenesis. Pediatr Res 22:335-338

13. Engle MJ, Brown DJ, Dehring AF 1986 Lactate metabolism in fetal type II pneumocytes. Lung 164:155-164

14. Longmore WJ, Mourning JT 1976 Lactate production in isolated perfused rat lung. Am J Physiol 231:351-354

15. Rhoades RA, Shaw ME, Eskew ML, Wali S 1978 Lactate metabolism in perfused rat lung. Am J Physiol 235:E619-E623

16. Fisher AB, Dodia C 1984 Lactate and regulation of lung glycolytic rate. Am J Physiol 246:E426-E429

17. Engle MJ, Brown DJ, Dehring AF, Dooley M 1988 Effect of lactate on glucose incorporation into fetal lung phospholipids. Exp Lung Res 14:121-129

18. Patterson CE, Koniki MV, Selig WM, Owens CM, Rhoades RA 1986 Integrated substrate utilization by perinatal lung. Exp Lung Res 10:71-86

19. Engle MJ, Dehring AF 1987 Palmitate and glucose oxidation by fetal type II pneumocytes. Biochim Biophys Acta 923:323-325

20. Lehninger AL 1982 The biosynthesis of lipids. In: Principles of Biochemistry. Worth Publishers Inc, New York, pp 583-614 